\title{
O ensino de História, a memória e o patrimônio cultural
}

Margarida Maria Dias de OLIVEIRA ${ }^{I}$

\section{RESUMO}

Esse texto tem por objetivo principal, registrar experiências vivenciadas no ensino de graduação de um Curso de História (UFRN), articulando-as com as discussões mais gerais da identidade do profissional de História e com as discussões epistemológicas desta área do ensino como objeto de pesquisa. Para seu desenvolvimento, parte-se da implantação do Projeto Político-Pedagógico daquele Curso e, com ele, de duas disciplinas: Memória e Patrimônio Histórico e Arquivística Histórica.

Palavras-chave: Formação do profissional de História; identidade profissional; ensino de História.

\section{O ilustre ausente nas discussões sobre o ensino de História: o curso de graduação}

A área de pesquisa do ensino de História, consolidada no Brasil, ainda não inclui - em toda sua potencialidade - as discussões sobre o ensino nas graduações de História.

Há alguns trabalhos referenciados e modelares, como o de CIAMPI, (2000), mas há necessidade de investimentos tanto em tornar o ensino de graduação como objeto de pesquisa quanto o ensino de História como objeto de pesquisa na formação inicial dos profissionais de História.

É notória a amplitude da área do ensino de História com a possibilidade de se estudar desde a formação de professores até a memória docente, passando pelas práticas educativas, a história desse ensino, da constituição dos cursos, entre outros.

' Professora do Departamento de História da Universidade Federal do Rio Grande do Norte. 
Contudo, o que se considera importante ressaltar e discutir, nesta oportunidade, é a necessidade de tornar o ensino de História objeto de problematização nos cursos de graduação, ou seja, torná-lo tema de pesquisa em um sentido amplo do termo, tanto em monografias, dissertações e teses, quanto em objeto de análise em componentes curriculares vinculados ou não a períodos e temáticas históricas, cursos de extensão, ações variadas de práticas como componentes curriculares, projetos de ensino, extensão, entre outros, Além disso, configura-se como condição básica para a reformulação das graduações desde discuti-lo em relação à constituição de uma didática da História² na educação básica até o enfrentamento do ensino superior como ensino de História, também.

À primeira vista, isso pode parecer tautologia. Contudo, muitas vezes, docentes e discentes e, sobretudo, os primeiros, dado o fato - absolutamente verdadeiro - de as universidades no Brasil concentrarem o maior percentual de pesquisa, comportam-se como se o ensino não fosse uma das suas ocupações fundamentais, ou como se a sala de aula fosse, apenas, uma interrupção nas suas atividades de pesquisa.

\section{O ensino de História como objeto de pesquisa dos profissio- nais de História: (des)entendimentos}

Partimos do pressuposto de que o profissional de História produz conhecimentos históricos em duas dimensões: na pesquisa e no ensino.

Na pesquisa, ele segue o seguinte roteiro:

Profissional de História

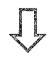

Problemática

$\sqrt{4}$

Tempo como categoria principal

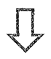

2 Compreende-se Iidáticá da História aqui no sentido que discute FREITAS, 2008; composta por finalidade, conteúdo e método de ensinar História. 
Investigação por meio de fontes<smiles></smiles>

Utiliza instrumentos teóricos e metodológicos

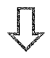

Consubstancia o resultado em textos acadêmicos

Em uma tentativa de síntese do ofício do profissional de História e de quais são suas atividades como produtor de conhecimento novo por meio da pesquisa, temos essas etapas de desenvolvimento das tarefas. Reconhecemos que essas atividades, por vezes, interpõem-se e que, na maioria das vezes, não seguem um caminho linear, mas permeado por refluxos, e que os instrumentais teóricos e metodológicos que escolhemos diferenciam a forma de abordagem da fonte, os conceitos que utilizamos, entre outros, contudo, o objetivo de visualizá-lo por meio de um gráfico tem a estrita intenção de compará-lo com outro momento da produção de conhecimento: 0 ensino.

No ensino, ele deve trabalhar com vários conhecimentos, mas o que deve nortear é a especificidade de produção do conhecimento histórico:

Como o profissional de História produz conhecimento histórico no ensino:

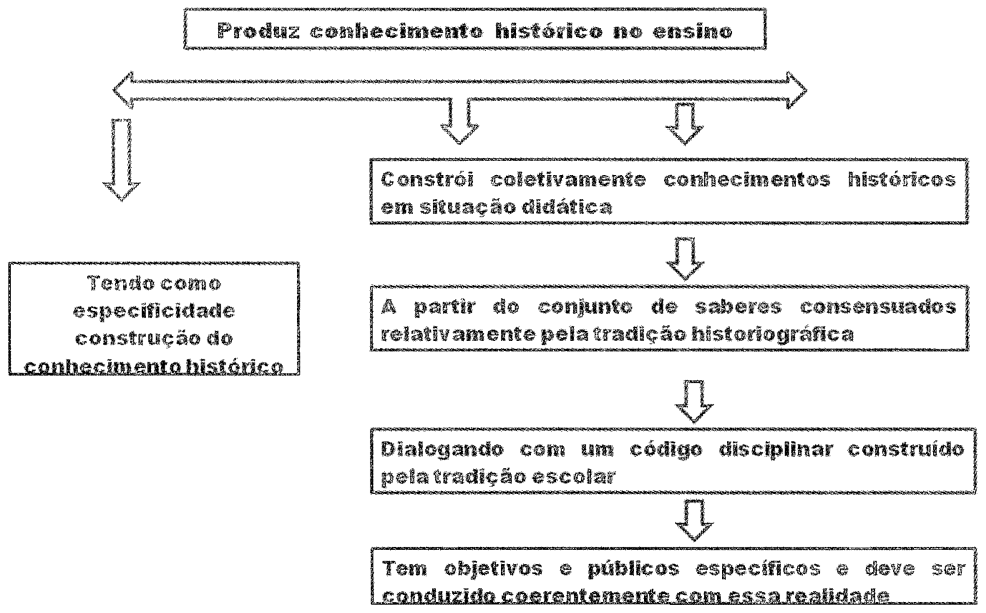


Ou seja, a forma específica - e os resultados provenientes dela - de produção do conhecimento histórico é o que deve nortear o diálogo com os outros campos do conhecimento e saberes necessários ao ensino de História, mas é a epistemologia da História que direciona toda essa interlocução.

Entendo que esse pressuposto focaliza na formação específica do profissional de História as discussões sobre o ensino, ou seja, coloca o ensino de História como uma problemática importante tanto no que diz respeito à discussão sobre a formação desse profissional e suas possibilidades de atuação por meio dessas duas dimensões (pesquisa e ensino) quanto no que concerne à interligação da teoria do conhecimento histórico e à produção do conhecimento em uma área de estudos, que é o ensino, como o são tantas outras dentro da historiografia.

Ora, a Associação Nacional de História - ANPUH, já nos Anais do I Simpósio Nacional de História, ocorrido em Marília/SP, em 1961, começava a defender essas ideias. Contudo, a complexidade delas, cristalizadas na frase "forma-se o professor como forma-se o pesquisador", não esclareceu nem contribuiu para minorar a dicotomia - historicamente construída - presente nos cursos de formação do profissional de História. A fórmula $3+1$ (três anos de formação específica e um de formação pedagógica) aprofundou o fosso entre as, assim chamadas, disciplinas de conteúdo e disciplinas pedagógicas, criando a falsa ideia de que a formação do licenciando, futuro profissional dedicado ao magistério (compreendido estritamente como na sala de aula formal), dar-se-ia exclusivamente pela formação proporcionada pelos departamentos, faculdades e/ou centros das Ciências da Educação.

Estudando os textos da Professora Emília Viotti da Costa, ou as deliberações do "Simpósio de Marília", ou, ainda, as primeiras avaliações realizadas pela Professora Alice Canabrava no primeiro número da Revista Brasileira de História em 1981, fica bastante evidente que essa cristalização teve o concurso de vários motivos, mas que esse debate - rico e vivo - precisa ser retomado e reposto em bases coerentes com o período histórico que vivemos e com as discussões acumuladas nesses cinquenta anos.

Com o intuito de contribuir nesse sentido basta lembrar que as Diretrizes Curriculares Nacionais, gestadas nos Núcleos Regionais da ANPUH (hoje Secções Regionais) e na Direção Nacional, concebeu a Prática como Componente Curricular (com 400 horas/aula de duração) e que, lamentavelmente, seja por 
coincidência de nomenclatura (associada automaticamente à Prática de Ensino), seja pelo olhar dicotômico naturalizado sobre a formação do pesquisador e do professor, muitos cursos de História não realizam a proposta de criar espaços para experiências de efetivação do ofício do profissional de História associadas às possibilidades de atuação desse profissional, como se configura nas DCN formuladas.

$\Lambda$ despeito de todo o avanço, considerando os novos parâmetros que norteiam as discussões teóricas e metodológicas da área do ensino de História, lamentavelmente, ainda há uma visão estereotipada de que todos que lidam com a sala de aula são pesquisadores do ensino, como se o fato de eu ser mulher me tornasse pesquisadora sobre as questões de gênero!

Há uma bibliografia e há questões epistemológicas específicas à área de pesquisa sobre o ensino de História, e elas precisam ser dimensionadas como problemática fundante da composição da identidade dos profissionais de História.

\section{A Universidade Federal do Rio Grande do Norte: Projeto Político-Pedagógico e o enfrentamento de atuações múltiplas do profissional de História}

Lim 2004, após intenso debate e anos de gestação, o Departamento de História da UFRN implantou um novo Projeto Político-Pedagógico que substituiu o que estava em vigor desde 1988.

Com esse novo PPP, foram implementadas duas novas disciplinas: Memória e Patrimônio Histórico e Arquivística Histórica.

Segunda as ementas dessas disciplinas, elas devem conter:

- Memória e Patrimônio Histórico: Memória e Patrimônio: história, cultura e identidade cultural. Evolução histórica do conceito de Patrimônio. Políticas públicas sobre o Patrimônio no Brasil.

- Arquivística Histónica: Introdução à arquivologia: informação de arquivos. Organização e administração de arquivos. Documento como matéria-prima dos arquivos. Documentos históricos: restauração, conservação e microfilmagem. Legislação arquivística e ética profissional. 
Concursada e tendo assumido em 2004, fiquei responsável pela implantação das disciplinas anteriormente mencionadas. Contudo, para além da prescrição do PPP, cabia agora pensar e executar um planejamento. A escolha para a efetivação da ementa deu-se da seguinte forma para cada um dos componentes curriculares.

No caso de Memória e Patrimônio Histórico, viu-se que a ementa privilegiava muito mais o conceito de patrimônio do que o de memória e resolveu-se dar um tratamento equitativo para os dois conceitos, dada a sua indissociabilidade e, além disso, a ligação com a historiografia. Outra opção foi pensar que a construção desse campo de saber pode levar o profissional de História à atuação em novos campos de atuação ou, sendo mais precisa, a ressignificação de antigos espaços, como museus, memoriais, arquivos ou centros culturais. 0 princípio utilizado para se pensar além do prescrito na ementa, esses novos enfoques, foi pensar isso tudo a partir da sociedade potiguar.

No que concerne à disciplina Arquivística Histórica, tirou-se o foco do documento histórico, ou seja, do documento que já cumpriu sua função administrativa e passa a ter importância só para a pesquisa, portanto, implementamos mais diálogo com a Arquivologia como ciência da informação, que tem por objetivos principais organizar, preservar e deixar acessível à informação. Inseriu-se uma discussão considerada fundamental, que é sobre a responsabilidade da UFRN, como instituição pública de ensino superior, na organização de acervos, instituindo parcerias, capacitando pessoal e consolidando experiências integradas de ensino, pesquisa e extensão. Da mesma forma que a primeira disciplina, decidiu-se por refletir que a construção desse campo de saber pode levar o profissional de História a atuar em equipes interdisciplinares em arquivos e que tudo isso só tem sentido se pensado a partir da sociedade potiguar.

A partir da experiência dos dois primeiros semestres (2004.1 e 2004.2), viu-se que seria necessário trabalhar no sentido de desnaturalizar os conceitos de memória, patrimônio, documentos. Os alunos chegavam às disciplinas como se esses existissem a priori. Sempre na ideia de que patrimônio restringe-se ao patrimônio edificado, que documentos importantes para a pesquisa são os antigos, relacionados ao período colonial e que memória era apenas a capacidade humana de lembrar.

Constatados tais problemas, começou-se a pensar em estratégias de trabalho de teoria da História que estão presentes nesses conceitos e em outros necessários 
às disciplinas. Construíram-se, assim, disciplinas "teórico-práticas", em que, sem descuidar das discussões necessárias para tais assuntos, buscou-se a "aplicação" efetiva do conhecimento produzido.

Viu-se a potencialidade inexplorada de diálogo dentro da comunidade universitária (com outras unidades acadêmicas, como museus universitários, arquivos, meios de comunicação) e com a sociedade potiguar como um todo.

\section{A sala de aula como espaço de construção do conhecimento}

A construção de memórias e suas problematizações vêm sendo, cada dia mais, incluídas na formação inicial dos professores. Além disso, os questionamentos sobre o patrimônio cultural e o diálogo com a museologia e a arquivologia.

$\mathrm{Na}$ Universidade Federal do Rio Grande do Norte - UFRN - em 2004, foi implantado um novo Projeto Político-Pedagógico inserindo disciplinas que abrem perspectivas para todos esses diálogos. Contudo, para além das disciplinas - como, aliás, propugna o PPP -, faz-se necessário repensar o que significam os nivelamentos, a organização dos componentes curriculares por áreas de conhecimento, a integração efetiva do ensino, pesquisa e extensão.

$\Lambda$ composiç̃̃o dos componentes curriculares em nivelamentos tem objetivos claros dentro da organização do PPP. Como elementos de um conjunto, supõe-se que eles integram a construção de saberes necessários ao exercício do profissional de História em suas duas dimensões: ensino e pesquisa.

Essas duas dimensões não significam, apenas, dois campos de trabalho. 0 ensino e a pesquisa podem ser exercidos em lugares tradicionais, como as instituições escolares e centros de pesquisa, mas também em espaços resignificados pela problematização do conhecimento histórico, como os museus, arquivos, memoriais. Faz-se fundamental, ainda, refletir sobre a atuação dos profissionais de História em espaços abertos com as tecnologias da informaç̧ão desde os jornais impressos e rádio, passando pelo cinema, televisão e a - ainda nova - Internet.

Em todos esses espaços, a atuação do profissional de História efetiva-se ou na sua dimensão de pesquisa (construindo conhecimento histórico, a fim de fornecer subsídios para elaborações de artigos, documentários, filmes, peças teatrais, sites, entre outros) ou de ensino (construindo conhecimento histórico para divulgação, planejando exposições, produzindo materiais didáticos, entre outros). 
Ora, faz-se, portanto, absolutamente necessáríio que os cursos de graduação criem espaços possíveis de vivências para esses tipos de atuação. Nesse sentido, os projetos de extensão são, potencialmente, experiências possíveis de integração, como o ensino, e podem frutificar em reflexões e produção de conhecimentos novos tanto em relação ao ensino e à profissionalização quanto em relação às problemáticas históricas.

Os alunos do Curso de História na UFRN cursam a disciplina Memória e Patrimônio Histórico como obrigatória para a modalidade Bacharelado, e como eletiva para a Licenciatura.

Oferecida no segundo semestre do Curso, é muito comum recebermos os discentes com uma visão muito naturalizada de patrimônio e memória como sinônimo de história.

Não é incomum, no início da disciplina, a expressão dos discentes pela defesa de um patrimônio potiguar, como se esse existisse a priori e ligado exclusivamente ao patrimônio de "pedra e cal" e com marco temporal delimitado pelo período colonial chegando, no máximo, às primeiras décadas do século XX. A associação de patrimônio ao que é antigo é bastante recorrente.

Por tudo isso, temos investido muito, durante a unidade inicial da disciplina e durante todo o seu desenvolvimento, na desnaturalização do patrimônio. Problematizamos não só trabalhando as informações históricas sobre quando, como surgiram essas primeiras preocupações, mas também fazendo com que reflitam sobre a relação com a escrita da história e os interesses sobre construção de memórias.

Na tentativa de proporcionar um "choque" sobre esse conceito naturalizado, iniciamos a disciplina com uma atividade de reconhecimento dos colegas de sala e de um primeiro questionamento sobre o conceito de patrimônio: pedimos que cada aluno leve um objeto, imagem - concretize de alguma forma - o que é considerado por ele como um patrimônio pessoal ou da sua família e os motivos pelos quais ele designa isso como patrimônio.

A constatação inicial é a forte relação entre patrimônio e afetividade e destes com a memória - nesse caso do indivíduo ou da família.

Em uma das turmas em que propus essa atividade, eu mesma levei um objeto e contei sua história para ser referenciado por mim como um patrimônio. 

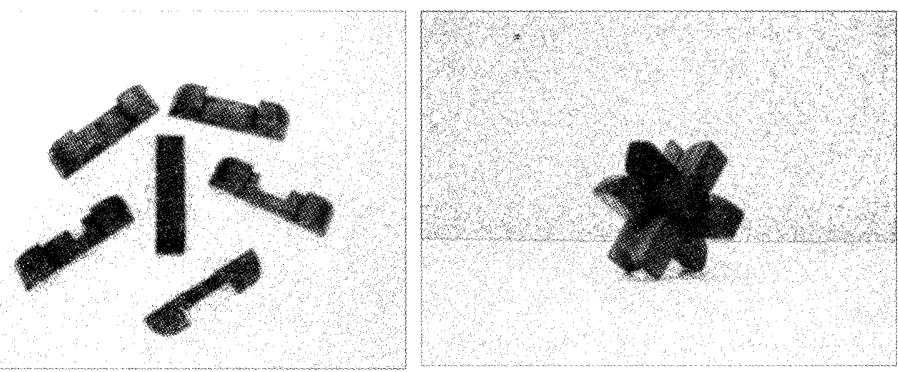

Meu pai, então trabalhador da construção civil na década de 50 do século $\mathrm{XX}$, conheceu um quebra-cabeça em um horário de almoço, tendo este sido apresentado por um indivíduo que, no momento de descanso, propôs que tentassem decifrar aquele jogo. Meu pai, curioso em muitas artes, dentre elas, a marcenaria, chegando em casa, copiou as peças, fabricando, ele seu próprio, quebra-cabeça.

Daquela data em diante, por muitas vezes, meu pai repetiu esse ato: pegou algum pedaço de madeira e, em variados tamanhos, produziu esse jogo, sempre para desafiar algum filho (e depois os netos). Em 1990, nasceu meu filho mais novo, e, mais uma vez, meu pai fabricou o jogo e deu de presente ao seu neto. Esse jogo ficou para a família como um símbolo de desafio.

Em 2003, quando defendi minha tese de doutorado, meus pais foram assistir à defesa. Na mesa que foi destinada para minha acomodação, ao lado dos livros que levei, de modo muito discreto, coloquei o quebra-cabeça montado. Meu pai olhou e sorriu. Com aquele gesto, eu dizia a ele que havia conseguido vencer mais um desafio, e ele, com seu sorriso, expressou que tinha entendido a minha mensagem.

Apresentei o jogo à turma e contei essa história, após ter ouvido as apresentações dos alunos. Essa atividade - na qual também me inseri - tem o objetivo de fazer conhecer-se um grupo que vai conviver durante quatro meses e, ao mesmo tempo, começar a trabalhar a polissemia da palavra patrimônio.

Como dito anteriormente, essa atividade inicial serve também para iniciar a desnaturalização do conceito de patrimônio, ou seja, vê-se claramente que há ali a construção de vários patrimônios ligados à história individual ou familiar. $\Lambda$ partir daí, pauta-se a questão: por que preservar?

Além disso, como estratégia de construção de atitudes, verifica-se a integração melhor da turma a reestruturação da relação professora-alunos, no sentido da 
percepção de que estamos lidando com indivíduos em toda sua humanidade e que a relação de poder perceptível em qualquer sala de aula (por mais que se procure a quebra desse espaço tradicional) pode, deve e é objetivo ali ser minorada.

Ora, o que tem ocorrido é a tentativa de implementar uma "nova cultura" para a sala de aula, cujo objetivo não seja estritamente a discussão de textos de autores consagrados, mas que a leitura desses textos (como preparação para as aulas) sirva como desencadeadora de reflexões, debates e construção de textos ou outros produtos de autoria do aluno.

\section{Primeiros passos, princípios norteadores, perspectivas}

Formada a primeira turma com o novo Projeto Político-Pedagógico, iniciou-se uma fase de avaliação. No caso das disciplinas sob nossa responsabilidade, esse momento de retificação de rumos tem um significado ainda maior.

0 princípio norteador das nossas experiências tem sido a integração das atividades de ensino, pesquisa e extensão. Os projetos de iniciação à docência (monitoria) têm produzido, entre outras coisas, o que denominamos de "kits didáticos" para as disciplinas. Constituem-se, basicamente em propostas de estratégias de sala de aula aliadas a materiais (textos, imagens, objetos, audiovisuais, etc.) que proporcionam atividades específicas do ofício do profissional de História como vivências com fins de construção do conhecimento?

Os Projetos de extensão, sobretudo na área de organização de acervos, têm favorecido que as aulas da disciplina Arquivística Histórica seja nos locais dos projetos, aliando teoria e prática em uma sintonia que tem gerado frutos significativos, sobretudo o fato de os alunos terem outro comportamento em relação às ciências da informação, percebendo-as como campos de diálogo possíveis da História e de perspectivas profissionais interdisciplinares.

Projeto de pesquisa: concepção do Memorial do Ministério Público do Estado do Rio Grande do Norte - pensa-se agora o serviço educativo do Memorial

Todos os projetos, sejam os de organização de acervos, seja os projetos de iniciação a docência têm frutificado em projetos de pesquisa que, por sua vez, têm gerado novas preocupações, como, por exemplo, como divulgar para a sociedade? Como mostrar à sociedade de que modo nossas pesquisas vinculam-se a

3 Para maiores detallies sobre essas propostas ver OLIVERIRA, 2009. 
ela? Na Feira de Ciência e Tecnologia (CIENTEC) de 2008, evento que se realiza há quinze anos na UFRN, um vídeo e três jogos foram produzidos e, por meio do desafio e da brincadeira, informavam como a memória, o patrimônio e o ensino, pesquisados pelo Departamento de História da UFRN, podem influir diretamente na história escrita, na história ensinada e na imagem que iremos deixar para os cidadãos do futuro.

\section{Referências}

ANPUH. Anais do I Simpósio Nacional dos Professores Universitários de História. Marília, 1962.

CANABRAVA, Alice Piffer. A Associação Nacional dos Professores Universitários de História. In: ANPUH, Revista Brasileira de História, v. 1, n. 1, mar. 1981.

CIAMPI, Helenice. A história pensada e ensinada: da geração das certezas à geração das incertezas. São Paulo: EDUC, 2000.

COSTA, Aryana Lima. O Curso de História da UFRN e o Projeto PolíticoPedagógico de 2004: discutindo a formação de um profissional. Trabalho de Conclusão de Curso (Bacharel-licenciado em História) - Centro de Ciências Humanas, Letras e Artes, UERN, Natal, 2007. (Digitado).

COSTA, Emília Viotti da. Sugestões para a melhoria do ensino da História no curso secundário. In: Revista de Pedagogia, Ano Sexto, vol. VI, 11/12, 1960.

COSTA, Emilia Viotti da. 0 problema da motivação no ensino de História. In: Revista de Pedagogia, XIII, São Paulo, USP, 1963.

COSTA, Emília Viotti da. Os objetivos do ensino da História no curso secundário. In: Revista de História, XXIX. São Paulo: USP, 1957.

COSTA, Emília Viotti da. 0 material didático no ensino da História. In: Revista de Pedagogia, X. São Paulo, USP, 1959.

FREITAS, Itamar. A pedagogia histórica de Jonathas Serrano: uma teoria do ensino de História para a escola secundária brasileira (1913/1935). São Cristovão: Editora UFS; Aracaju: Fundação Oviêdo Teixeira, 2008.

OLIVEIRA, Margarida Maria Dias de. De um curso de água a outro: transição assistida para o ofício do historiador. Projeto de Iniciação a Docência (Monitoria), PROGRAD-UFRN: Natal, 2005 
OLIVEIRA, Margarida Maria Dias de. O que a memória guardou: conhecimentos teórico-práticos da cultura material no exercício da docência do profissional de História. Projeto de Iniciação a Docência (Monitoria), PROGRAD-UFRN: Natal, 2007

OLIVEIRA, Margarida Maria Dias de Oliveira (Organizadora). Como se formam os professores de História: vivências e experiências na iniciação à docência. Natal,RN: EDUTRRN, 2009.

OLIVEIRA, Margarida Maria Dias. Licenciado em História, Bacharel em História, His toriador: desafios e perspectivas em torno de um profissional. Revista Eletrônica História Hoje. (online). Disponível em: http://www.anpuh.uepg.br/historia-hoje/ volln4/licenciado.ht. Data de acesso: 01 dez. 2009

UFRN/CCHLA/IEHIS. Projeto Político-Pedagógico do Curso de Histónia. Natal, 2004.

\section{The teaching of history, memory and cultural heritage}

ABSTRACT

This article aims to record the main experiences in teaching an undergraduate history course(UFRN) linking them with the more general discussions of the history professional identity and the epistemological discussions, educational history as a research. For the development part of the implementation of political-pedagogical project that course and, with it, the two disciplines: Memory and the Historical and Archival Historical.

Key-words: 'Training of professional history, professional identity, teaching of history. 